\title{
Isolation and Antibiogram of Nonfermentative Gram Negative Bacilli in various Clinical Specimens in a Tertiary Care Hospital, Jaipur, India
}

\author{
Jitendra $^{1}$, Shiv Kumar ${ }^{1 *}$, Sheetal Sharma ${ }^{2}$, Jogender ${ }^{1}$ and Suman Rishi ${ }^{1}$ \\ ${ }^{1}$ Department of Microbiology, NIMS Medical College, Jaipur, Rajasthan, India \\ ${ }^{2}$ Department of Microbiology, Pacific Medical College, Udaipur, Rajasthan, India \\ *Corresponding author
}

\begin{abstract}
Keywords
Nonfermenters,

Antibiogram,

Modified Kirby-

Bauer disc diffusion

method,

Nosocomial

infections,

Healthcare

associated

infections,

Polymyxin-B,

Colistin.

Article Info

Accepted:

12 October 2017

Available Online:

10 December 2017 ability to show resistance for commonly used antibiotics. These organisms isolated from clinical specimens with increasing frequency. So this study planned to isolate and antibiogram of Non-fermentative gram negative bacilli in various clinical specimens at tertiary care hospital at Jaipur. The present study was carried out on 49 of strains of Nonfermenters isolated from 397 non repetitive clinical samples like Pus, Wound discharge, Blood culture, Urine, Sputum, Ear discharge, Body fluid, ET Secretions and CSF etc. from all age's group. Conventional bacteriological methods were used for identification non fermenting gram negative bacilli and susceptibility testing was performed with the help of the Modified Kirby-Bauer disc diffusion method. This study comprises of 49 isolates of Non Fermentative Gram Negative Bacilli from total of 397 clinical specimens, collected from in- patients admitted to various departments during a period of 6 months. Pseudomonas aeruginosa was the most common isolate (57.14\%) while Acinetobacter baumannii $(24.48 \%)$ was the second most common isolated followed by Pseudomonas fluorescens (14.28\%) and Acinetobacter lwoffii (4.08\%). Among all clinical samples Pus yield maximum isolates of NFGNB i.e. 15(30.61\%) followed by same account of Urine $8(16.32 \%)$ and Sputum $8(16.32 \%)$. Most sensitive drug against NFGNB were Polymyxin-B (100\%) and Colistin (100\%) followed by Imipenem (81.63\%), Amikacin (71.42\%). Pseudomonas aeruginosa and Acinetobacter baumannii have emerged as the most common Nonfermentative gram negative bacilli causing human infections. Alarming resistance rate was found towards commonly used antibiotics. Polymyxin B and Colistin showed excellent susceptibility against such bacteria followed by Imipenem and amikacin.
\end{abstract}

\section{A B S T R A C T}

Non Fermentative Gram Negative Bacilli were regarded to be Nonpathogenic and Contaminants in the past. Recently these bacilli became impending pathogenic with the

\section{Introduction}

Nonfermenters are group of bacteria that are aerobic, non sporing, gram negative rod shaped bacilli and do not utilize carbohydrates as source of energy or degrade them by various metabolic pathways other than fermentation. These organisms although frequently considered to be commensals or contaminants, but the pathogenic potential of these organisms has been established beyond doubt because of their frequent isolation from clinical specimens and their association with the disease (Koneman et al., 2006). 
We encounter many problems with these organisms because they are invariable resistance to common disinfectants like as chlorhexidine and quaternary ammonium compounds and now a day they account approximate $15 \%$ of all bacterial isolates of any clinical laboratory (Malini et al., 2009).

Various organisms are present in these groups like Pseudomonas, Acinetobacter, Alkaligenes, Burkholderia, Moraxella, Strenotrophomonas, Flavobacter, Oligella, Flavimonas etc. (Meharwal et al., 2002).

Pseudomonas aeruginosa is a common inhabitant of soil and moist environments (Minhas Akbar et al., 2014; Ronald et al., 1969). In hospitals, Pseudomonas Aeruginosa can be isolated from a variety of sources, including respiratory therapy equipments, antiseptics, soap, sinks, mops, medicines, physiotherapy equipment and hydrotherapy pools (Pollack et al., 1995).

Data from more recent studies continue to show Pseudomonas aeruginosa as the second most common cause of nosocomical pneumonia, health care associated pneumonia and ventilator associated pneumonia (Gaynes et al., 2005; Kollef et al., 2005).

Acinetobacter species are ubiquitous in nature and have been found on or in soil, water, animals and humans. Acinetobacter baumannii is known to be recoverable from the skin, throat and rectum of humans and has been reported to be a healthcare-acquired colonizer of the respiratory tract. According to the Centres for Disease Control and Prevention (CDC), the species A. baumannii accounts for nearly $80 \%$ of reported Acinetobacter infections. This prolonged survival in the healthcare environment along with multidrug resistance, colonization potential, and contact transmission (hands, instruments, equipment) are some of the challenging factors in Acinetobacter prevention and control (An APIC guide, 2010).

Members of the genus Acinetobacter usually invade compromised hosts and are seen in patients who have undergone endotracheal intubation, peritoneal dialysis, or central venous catheterization (Kiran Chawla et al., 2013).

Pseudomonas aeruginosa and Acinetobacter species in particular are most often associated with carbapenem resistance. Carbapenem resistance appears to be due to metallo- $\beta$ Lactamase.

Excessive and indiscriminate used of broad spectrum antibiotics also responsible for antibiotic resistance (Mehta et al., 2007). Patients become susceptible to non fermentive bacterial infections after abusive use of wide spectrum antimicrobial agents, prolonged treatment with immunosuppressive drugs, prolonged hospital stay, inadequate mechanical instruments like tracheostomy, catheterization, in case of burns, low birth weight babies or radiation (Gerard et al., 1991).

The prevalence and rates of resistance in these organisms to available antimicrobials are increasing of particular concern is their resistance to $\beta$-lactams antibiotics, which is usually mediated by $\beta$-lactamase production. Widespread use of extended spectrum $\beta$ lactams antibiotics has resulted in the formation of potent enzymes that are able to inactivate many of the new generation of antimicrobial agents.

Extended spectrum $\beta$-lactamase (ESBL) are enzymes with the ability to hydrolyze the extended spectrum Cephalosporins, such as Cefotaxime, Ceftazidime and Cefoperazone. (Shahla Mansouri et al., 2012). 
Due to increasing frequency as isolation and increasing resistance against various antibiotics, it is important to know prevalence and antibiogram of Nonfermentive gram negative bacilli in hospital settings.

\section{Materials and Methods}

This Descriptive cross sectional study was carried out in the Bacteriology Department of Microbiology of National Institute of Medical Sciences (NIMS) University, Jaipur, DistrictJaipur, Rajasthan, India for a period of six months (January 2017 to June 2017).

A total of 397 clinical specimens were found culture positive in the laboratory during the study period.

The organisms isolated and identified provisionally as NFGNB $(\mathrm{n}=49)$ were identified further by using a standard protocol for identification. (Koneman et al., 2006).

All Non-repetitive isolates of NFGNB were collected from various clinical Specimens like Pus, Wound discharge, Blood culture, Urine, Sputum, Ear discharge, Body fluid, ET Secretions and CSF etc from Patients of all age group and both sex attending OPD, IPD, ICU and Wards in hospital, during the study period. Isolation of various isolates was confirmed by several of test like colony characters, morphology (Gram's stain), pigment production, motility (by hanging drop) and other biochemical tests like Catalase, Oxidase test, Indole, Methyl red, Voges Proskauer, Citrate utilization test, Urease test and Triple sugar iron Test, Oxidation/fermentation for glucose, lactose, xylose, mannitol and maltose (Hugh and Leifson's media), Lysine and Ornithine decarboxylase and Arginine dihydrolase activity, ONPG test, Esculin test etc. were done for isolation of the non-fermentative Gram negative bacilli.

\section{Antimicrobial susceptibility}

Antibiotic susceptibility testing was done by Modified Kirby Bauer's disc diffusion method as per CLSI guidelines 2017 using commercially available discs. Escherichia coli ATCC 25922 and Pseudomonas aeruginosa ATCC 27853 were used as control strains.

\section{Results and Discussion}

A total 49 strains of nonfermenters were isolated from 397 various non-repetitive various clinical samples. Incidence of nonfermentative gram negative bacilli isolates from clinical samples was $12.34 \%$.

Pseudomonas aeruginosa was the most common isolate $(57.14 \%)$ while Acinetobacter baumannii (24.48\%) was the second most common isolated followed by Pseudomonas fluorescens (14.28\%) and Acinetobacter lwoffii (4.08\%).

Out of total 397 samples 226 (56.92 \%) samples from Male while 171 (43.07\%) from Female Patient.

Out of total 397 samples, maximum from age group between 21-30 years i.e. $23.17 \%$ while minimum from $<10$ years of age i.e. $7.30 \%$.

The present had maximum Urine samples (38.03\%), followed by Pus $(21.66 \%)$, Sputum (10.07\%), High vaginal swab (4.78\%), ET secretion (4.28\%), CSF (4.03\%) Ear swab (3.77\%), Pleural fluid $(3.52 \%)$, Blood $(2.77 \%)$, Catheter tip (01\%), Semen (1\%), Nasal swab (0.5\%), Ascetic fluid (0.25\%) and Bile fluid (0.25\%) (Fig. 1).

Maximum samples of over study were sterile (44.33\%). Gram Positive Cocci (25\%) predominantly isolated in our study, followed by Gram negative bacilli other than NF GNB 
(13\%), NF GNB (12.34\%), Normal flora (4\%) and Candida species (2\%) (Fig. 2).

Maximum Nonfermentive GNB isolated from Pus sample (15) followed by same amount of Urine (8) and Sputum (8), Ear swab (6), ET secretion (5), Blood (3) and (1) each from Catheter tip and Bile fluid (Table 1).

Out of 28 isolate of Pseudomonas aeruginosa, $25(89.28 \%)$ isolates producing Blue- Green pigment (Pyocyanin), 1 (3.57\%) was Nonpigmented, 2 (7.14\%) isolates producing Brown Red pigment (Pyomelanin) (Fig. 3 and 4).

\section{Antibiotic sensitivity testing results}

Out of 49 isolates of NFGNB were processed for Antibiotic susceptibility testing was done by Modified Kirby Bauer's disc diffusion method as per CLSI guidelines 2017 using commercially available discs.

The antimicrobial sensitivity testing of isolated NFGNB as a pathogen showed that $100 \%$ of $P$. aeruginosa were sensitive to Polymyxin B and Colistin, $86 \%$ were sensitive to Imipenem, $75 \%$ were sensitive to Amikacin, $61 \%$ were sensitive to Ceftazidime-Clavulanate, $\quad 57 \%$ for Gentamicin and Piperacillin- Tazobactum, $53 \%$ for Cefepime, Ciprofloxacin and Meropenem. $50 \%$ sensitive to Ceftazidime and Aztreonam. $43 \%$ sensitive to Tobramycin. $39 \%$ sensitive to Cefotaxime. $36 \%$ sensitive to Ticarcillin and Piperacillin. $25 \%$ sensitive to Ceftriaxone $14 \%$ sensitive to Cotrimoxazole. $4 \%$ sensitive to Amoxyclav. (Table 2 and Fig. 5).

While the second most isolated NFGNB, $A$. baumannii showed highest sensitivity $100 \%$ sensitive to Polymyxin B and Colistin, 67\% were sensitive to Imipenem, 59\% were sensitive to Amikacin, $42 \%$ were sensitive to
Ceftazidime-Clavulanate, Aztreonam and Meropenem 34\% for Gentamicin and Piperacillin- Tazobactum, Ceftriaxone, Tobramycin, Cotrimoxazole. 26\% sensitive for Cefepime, Ceftazidime. $25 \%$ sensitive to Piperacillin. $17 \%$ sensitive to Ticarcillin, Ciprofloxacin and Cefotaxime, $8 \%$ sensitive to Amoxyclav.

While Pseudomonas fluorescens and Acinetobacter lwoffii showed $100 \%$ sensitivity to Polymyxin B and Colistin and total resistance to Amoxyclav.

\section{Demographic profile of patients included in study}

In our study higher samples were received in the age group of $21-30$ years $(23.17 \%)$ with over all preponderance of males $(56.92 \%)$.This observations were compatible with study done by Jayapriya Sukumaran et al., (2014).

\section{Isolation of non- fermenters GNB}

Among the diverse Clinical Specimens, in our study, the NFGNB were predominant in Pus samples $(30.61 \%)$ followed by Sputum (16.32\%) and Urine (16.32\%). These result comparable with the study done by Kamalraj et al., (2015), Dipak Bhargava et al., (2015), Malini et al., (2009). However, NFGNB predominantly reported in Ear Swabs (36\%) by Aamal et al., (2016).

Non fermenting Gram negative bacilli considered to be contaminants in the past have now emerged as important major pathogenic organisms. Previous studies reported varied isolation rates of NFGNB. In our study, isolation rate of NFGNB was $12.34 \%$, which is in agreement with the study conducted by Hariom Sharan et al., (2016) where the isolation rate was $13.82 \%$. Our study is not in agreement with the studies 
conducted by Sidhu et al., (2010) (45.9\%) and Vijaya et al., (2000) $21.80 \%$ where very high isolation rate was reported. However, studies conducted by Malini et al., (2009) and Bruno et al., (2011) showed very low isolation rate of $4.5 \%$ and $2.18 \%$ respectively.

Table.1 Distribution of NF GNB species in various clinical samples

\begin{tabular}{|l|c|c|c|c|c|c|c|c|c|c|}
\hline $\begin{array}{l}\text { NF GNB } \\
\text { Species }\end{array}$ & Urine & Sputum & Pus & ET & $\begin{array}{l}\text { Ear } \\
\text { Swab }\end{array}$ & Blood & $\begin{array}{l}\text { Catheter } \\
\text { tip }\end{array}$ & $\begin{array}{l}\text { Bile } \\
\text { Fluid }\end{array}$ & $\begin{array}{l}\text { Total } \\
(\mathrm{n}=49)\end{array}$ & $\begin{array}{l}\text { Percenta } \\
\text { ge (\%) }\end{array}$ \\
\hline $\begin{array}{l}\text { Pseudomonas } \\
\text { aeruginosa }\end{array}$ & 3 & 4 & 9 & 3 & 6 & 1 & 1 & 1 & 28 & 57.14 \\
\hline $\begin{array}{l}\text { Acinetobacter } \\
\text { baumannii }\end{array}$ & 3 & 2 & 3 & 2 & - & 2 & - & - & 12 & 24.48 \\
\hline $\begin{array}{l}\text { Pseudomonas } \\
\text { fluorescens }\end{array}$ & 1 & 1 & 2 & 1 & 2 & - & - & - & 7 & 14.28 \\
\hline $\begin{array}{l}\text { Acinetobacter } \\
\text { lwoffii }\end{array}$ & 1 & - & 1 & - & - & - & - & - & 2 & 4.08 \\
\hline
\end{tabular}

Table.2 Species wise antibiotic susceptibility pattern of nonfermentative Gram negative bacilli

\begin{tabular}{|c|c|c|c|c|c|c|c|c|}
\hline \multirow[t]{2}{*}{ Name of the antibiotic } & \multicolumn{2}{|c|}{$\begin{array}{l}\text { Pseudomonas } \\
\text { aeruginosa } \\
(\mathrm{n}=\mathbf{2 8})\end{array}$} & \multicolumn{2}{|c|}{$\begin{array}{l}\text { Acinetobacter } \\
\text { baumannii } \\
(\mathrm{n}=12)\end{array}$} & \multicolumn{2}{|c|}{$\begin{array}{l}\text { Pseudomonas } \\
\text { fluorescens } \\
(\mathbf{n}=7)\end{array}$} & \multicolumn{2}{|c|}{$\begin{array}{l}\text { Acinetobacter } \\
\text { lwoffii } \\
(\mathrm{n}=2)\end{array}$} \\
\hline & $\begin{array}{l}\begin{array}{l}\text { No. of } \\
\text { isolates }\end{array} \\
\end{array}$ & $\%$ & $\begin{array}{l}\text { No. of } \\
\text { isolates }\end{array}$ & $\%$ & $\begin{array}{l}\text { No. of } \\
\text { isolates }\end{array}$ & $\%$ & $\begin{array}{l}\begin{array}{l}\text { No. of } \\
\text { isolates }\end{array} \\
\end{array}$ & $\%$ \\
\hline Amoxyclav & 1 & 3.57 & 1 & 8.33 & 0 & 0 & 0 & 0 \\
\hline Ticarcillin & 10 & 35.71 & 2 & 16.66 & 2 & 28.57 & 1 & 50 \\
\hline Piperacillin & 10 & 35.71 & 3 & 25 & 2 & 28.57 & 1 & 50 \\
\hline Piperacillin-Tazobactum & 16 & 57.14 & 4 & 33.33 & 3 & 42.85 & 2 & 100 \\
\hline Cefepime & 15 & 53.57 & 3 & 26 & 2 & 28.57 & 1 & 50 \\
\hline Cefotaxime & 11 & 39.28 & 2 & 16.66 & 2 & 28.57 & 0 & 0 \\
\hline Ceftriaxone & 7 & 25 & 4 & 33.33 & 2 & 28.57 & 2 & 100 \\
\hline Ceftazidime & 14 & 50 & 3 & 26 & 3 & 42.85 & 1 & 50 \\
\hline Ceftazidime-Clavulanate & 17 & 60.71 & 5 & 41.66 & 4 & 57.14 & 2 & 100 \\
\hline Amikacin & 21 & 75 & 7 & 58.33 & 6 & 85.71 & 1 & 50 \\
\hline Gentamicin & 16 & 57.14 & 4 & 33.33 & 4 & 57.14 & 2 & 100 \\
\hline Tobramycin & 12 & 42.85 & 4 & 33.33 & 2 & 28.57 & 0 & 0 \\
\hline Ciprofloxacin & 15 & 53.57 & 2 & 16.66 & 3 & 42.85 & 0 & 0 \\
\hline Aztreonam & 14 & 50 & 5 & 41.66 & 3 & 42.85 & 1 & 50 \\
\hline Imipenem & 24 & 85.71 & 8 & 66.66 & 6 & 85.71 & 2 & 100 \\
\hline Meropenem & 15 & 53.57 & 5 & 41.66 & 4 & 57.14 & 2 & 100 \\
\hline Cotrimoxazole & 4 & 14.28 & 4 & 33.33 & 1 & 14.28 & 1 & 50 \\
\hline Polymyxin- B & 28 & 100 & 12 & 100 & 7 & 100 & 2 & 100 \\
\hline Colistin & 28 & 100 & 12 & 100 & 7 & 100 & 2 & 100 \\
\hline
\end{tabular}




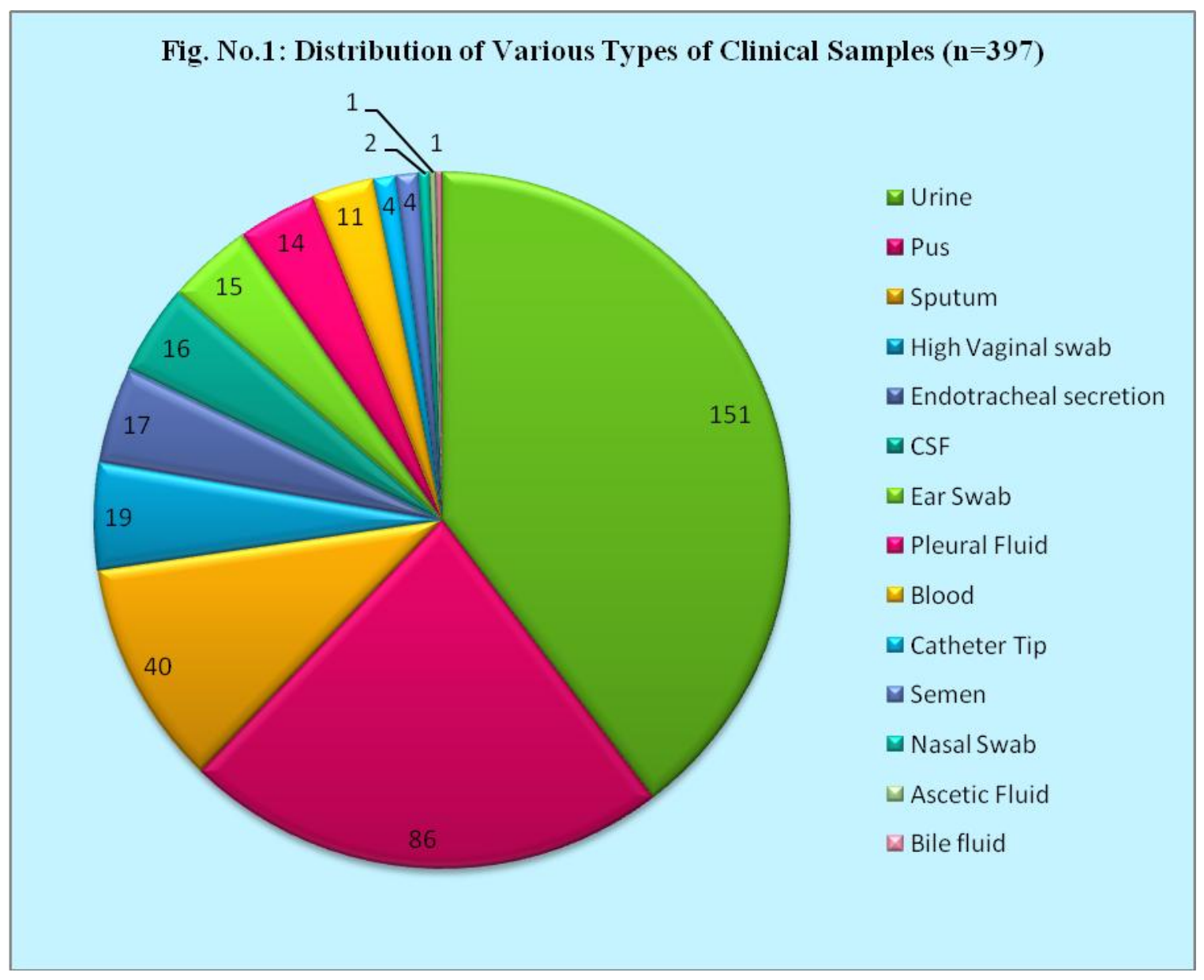

Fig. No. 2 : Isolation Rate of Various Organisms in Samples

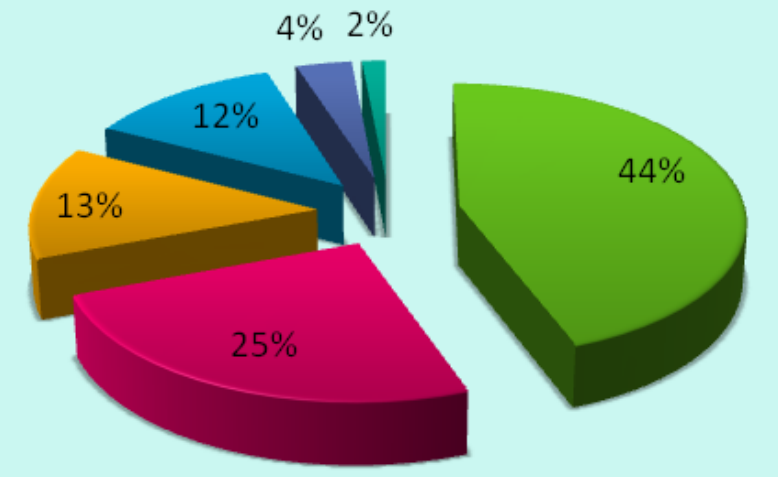
$\square$ Sterile
口 GPC
$\square$ GNB (other than NF GNB)
$\square$ NFGNB
$\square$ Normal Flora
$\square$ Candida Species 
Fig. No. 3 : Percentage wise Distribution of Pigment producing Pseudomonas aeruginosa

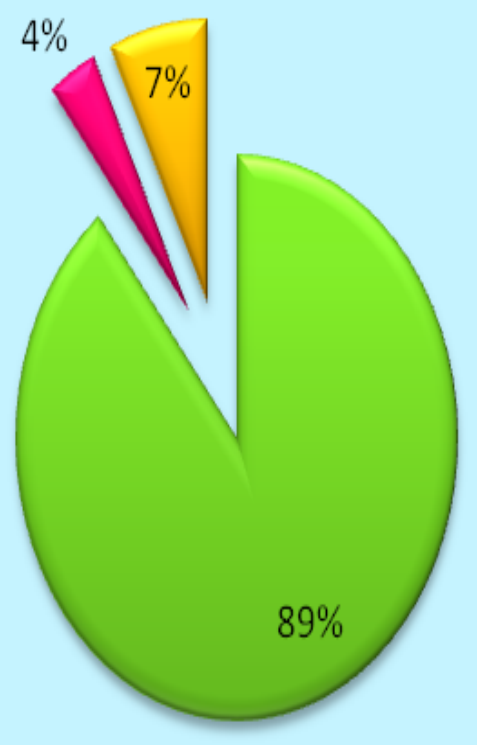

घBlue- Green

von-Pigmented

$\square$ Brown Red pigmented

Fig.4 Antibiotic sensitivity pattern of Pseudomonas aeruginosa showing pyomelanin pigment

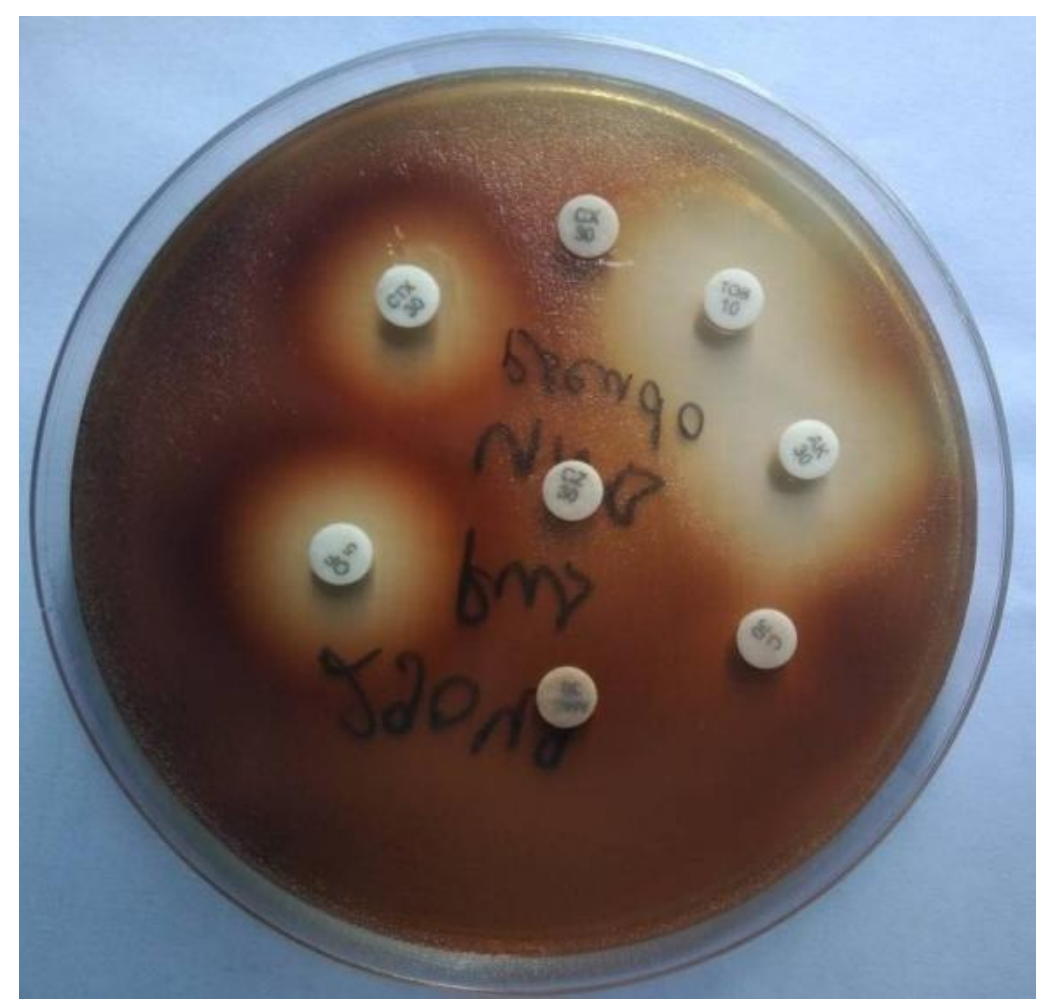


Fig. No. 5: Rate of Antibiotic Sensitivity Pattern in Nonfermentative Gram Negative Bacilli

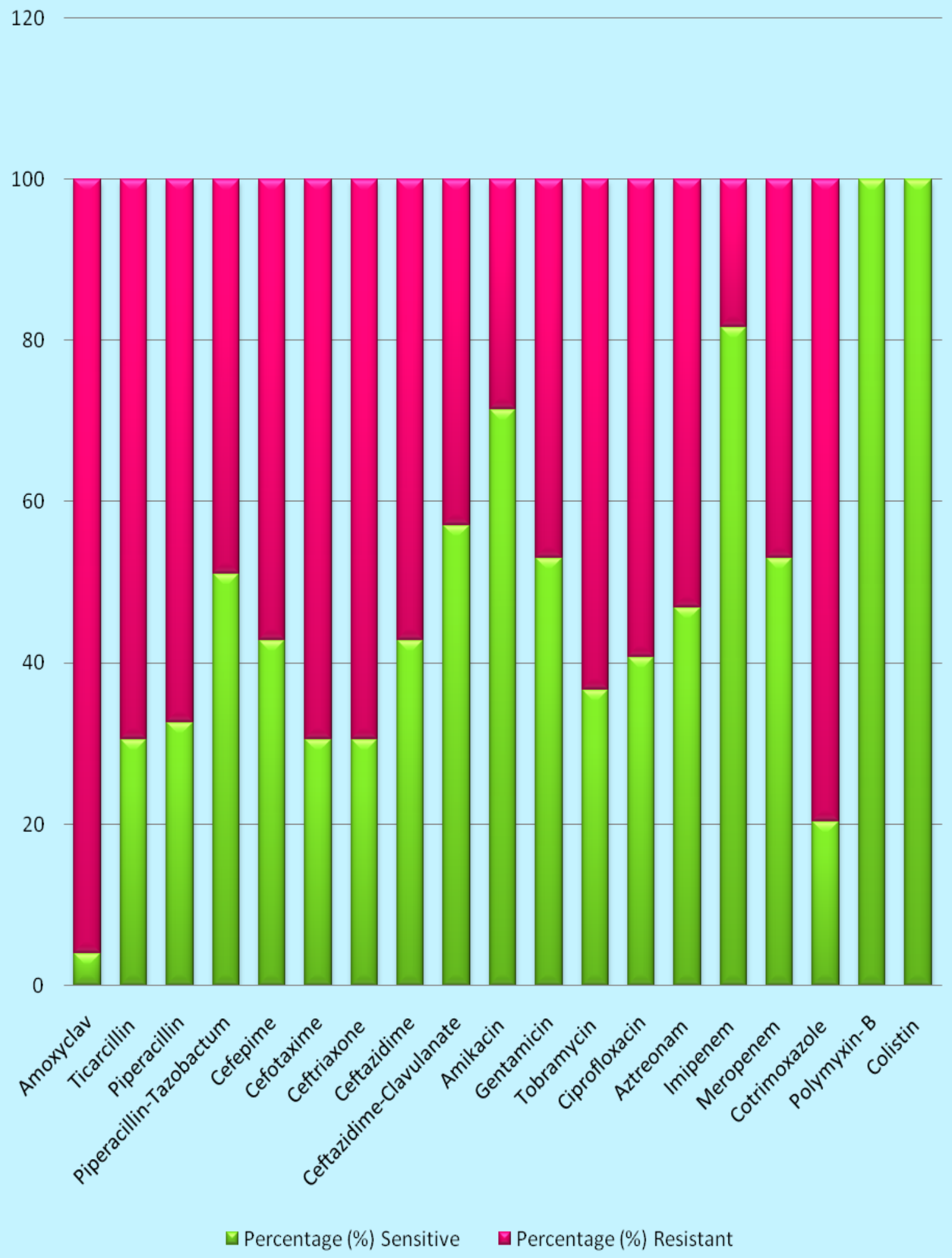


Pseudomonas aeruginosa was found to be commonest nonfermenter in previous studies followed by Acinetobacter baumannii and this is in concordance to our results.

In the present study the most common NFGNB isolate was Pseudomonas aeruginosa $57.14 \%$. This result has correlated well with the study conducted by Malini et al., (2009) reported 64.4\% while Arora et al., (2010) reported $72.83 \%$,Vijaya et al., (2000) reported $78.94 \%$ while Juyal et al., (2013) reported a low isolation rate of $38.21 \%$ Pseudomonas aeruginosa. The variation is likely due to number and type of clinical samples and geographical area of the study.

In the present study the second commonest isolate was Acinetobacter baumannii $24.48 \%$. The result correlated well with the study conducted by Malini et al., (2009) reported $25.3 \%$. However, Juyal et al., (2013) reported $29.27 \%$ in their study while Arora et al., (2010) reported $8.4 \%$. The variation is likely due to number and type of clinical samples and geographical area of the study.

Majority of Pseudomonas aeruginosa $(32.14 \%)$ were isolated from pus specimens. This is comparable with the study conducted by Hariom Sharan et al., (2016) who reported $26.32 \%$ isolation rate of Pseudomonas aeruginosa from Pus samples as dominant pathogen. However Dipak Bhargava et al., (2015) reported $43.9 \%$ Pseudomonas aeruginosa from Pus samples.

In our study, majority of Acinetobacter baumannii were from Pus and Urine specimen (25\% each). This is similar to study done by Kamalraj et al., (2015)

However Sundaram Mohan et al., (2016) reported 56.52\%. Acinetobacter baumannii from Respiratory Specimens such as Endotracheal Tube and Sputum.
In Present Study, Isolation rate of Pseudomonas fluorescens was $14.28 \%$ and nearby isolation rate reported by Dipak Bhargava et al., (2015). However Jayapriya Sukumaran et al., (2014) reported only $2.6 \%$ Pseudomonas species.

Isolation rate of Acinetobacter lwoffii in our study was $4.08 \%$. Similar isolation rate reported by Dipak Bhargava et al., (2015) $3.6 \%$.

Different types of pigments are produced by nonfermenters, which are helpful in making their species identification e.g. Pseudomonas, Roseomonas, Stenotrophomonas maltophila etc. Pseudomonas aeruginosa produces Pyocyanin pigment in $90-96 \%$ of strains.

In our study out of 28 isolate of Pseudomonas aeruginosa, 25(89.28\%) isolates producing blue green pigment (pyocyanin), similar observation was made in a study of Gokale et al., (2012) that showed 94\% of Pseudomonas aeruginosa isolates produced Pyocyanin pigment.

\section{Antibiotic sensitivity and resistance of non fermenters GNB}

In present study Pseudomonas aeruginosa showed $100 \%$ sensitivity to Polymyxin B and Colistin. This result is in concordance to study done by Hariom Sharan et al., (2016). However Vikas Jain et al., (2015) reported $71.43 \%$ sensitivity to Colistin and $78.57 \%$ sensitivity to Polymyxin B.

After Polymyxin B and Colistin Pseudomonas aeruginosa was highly sensitive to Imipenem $(85.71 \%)$. It correlates well with the work of Kamalraj et al., (2015) and Vikas Jain et al., (2015) where sensitivity to imipenem was $88.4 \%$ and $78.57 \%$, respectively. However, only $58.26 \%$ sensitivity reported against imipenem by Syed Hussain et al., (2015). 
Pseudomonas aeruginosa was $75 \%$ sensitive to Amikacin in our observation. Which is very similar to study done by Hariom Sharan et al., (2016) where sensitivity to amikacin was $80 \%$. But Vikas Jain et al., (2015) reported only $50.00 \%$ sensitivity to Amikacin.

In present study, Very low sensitivity was present for Amoxyclav (3.57\%) and Cotrimoxazole (14.28\%). However Vikas Jain et al., (2015) reported $50.00 \%$ sensitivity to Amoxyclav and Hariom Sharan et al., (2016) reported $28 \%$ sensitivity to Cotrimoxazole.

Acinetobacter baumannii and Pseudomonas aeruginosa showed $100 \%$ sensitivity to Polymyxin B and Colistin. This result is in concordance to study done by Syed Hussain et al., (2015). However Vikas Jain et al., (2015) reported $80.00 \%$ sensitivity to both Colistin and Polymyxin B. In our study, Acinetobacter baumannii showed very low sensitivity against amoxyclav (8.33\%), ticarcillin $(16.66 \%)$, cefotaxime $(16.66 \%)$ and ciprofloxacin $(16.66 \%)$. Similar results had given by Hariom Sharan et al., (2016) Sundaram Mohan et al., (2016) and Syed Hussain et al., (2015). However Kamalraj et al., (2015) reported $66.66 \%$ sensitivity against Cefotaxime and $25 \%$ sensitivity to Amoxyclav.

In our study, other isolates were Pseudomonas fluorescens and Acinetobacter lwoffii. In them Pseudomonas fluorescens was $100 \%$ sensitivity to Polymyxin B and Colistin. This result is in concordance to study done by Hariom Sharan et al., (2016). Pseudomonas fluorescens was totally resistant to Amoxyclav and had very low sensitivity against Cotrimoxazole. It correlates well with the work of Hariom Sharan et al., (2016).

Acinetobacter lwoffii was very few to determine the antibiotic sensitivity. In present study over all Nonfermentive Gram Negative
Bacilli was highly sensitive to Polymyxin B and Colistin (100\%). This result is in concordance to study done by Hariom Sharan et al., (2016).

Nonfermentive Gram Negative Bacilli showed high resistance to Amoxyclav $(95.91 \%)$ and Cotrimoxazole $(79.59 \%)$ in present study. Our result is comparable to Hariom Sharan et al., (2016) and Sundaram Mohan et al., (2016) However Vikas Jain et al., (2015) reported less resistance to Amoxyclav as (52.52\%).

\section{Acknowledgement}

The authors are thankful to the Department of Microbiology of National institute of medical sciences (NIMS) Medical College, Jaipur (Raj.) for providing necessary laboratory facilities to carry out this work.

\section{References}

Aamal Ghazi Mahdi Al-Saadi, Alaa Fahim Abbas, Thahir Abid D'asheesh. 2016. Identification of nonfermenting gram negative bacilli from patient in alDivaniya city and detection of their virulence factors. International Journal of Advanced Research. 4(3): 855-861.

Arora D, Jindal N, Kumar R. 2011. Emerging antibiotic resistance in Pseudomonas a challenge. International Journal Pharmacy Pharmaceutical Sciences. 3(2):82-84.

Bruno D, Nishino MK, Priore WN, Remus PR, do Carmo AA, Stefanello VB. 2011. Prevalence of Gram-negative non-fermenters patients in Porto Alegre RS. Journal Brasileiro de Patologia e Medicina Laboratorial. 47: 529-34.

Clinical and laboratory standards institute (CLSI). 2017. Performance standards for antimicrobial Susceptibility testing, $27^{\text {th }}$ Ed Wayne, USA. 
Dipak Bhargava, Sanjay Kar and Mukesh Saha. 2015. Prevalence of NonFermentative Gram Negative Bacilli Infection in Tertiary Care Hospital in Birgunj, Nepal Int.J.Curr.Microbiol. App.Sci 4(7): 301-307.

Gaynes, R. and J. R. Edwards. 2005. Overview of nosocomial infections caused by gram negative bacilli. Clin. Infect. Dis. 41: 848-854.

Gerard J. Osterhout, Virginia H. Shull and James D. Dick. 1991. Identification of Clinical Isolates of Gram-Negative Nonfermentative Bacteria by an Automated Cellular Fatty Acid Identification System. Journal of clinical microbiology. 29(9): 18221830.

Gokale SK, Metgud SC. 2012. Characterization and antibiotic sensitivity pattern of non fermenting gram negative bacilli from various clinical samples in a tertiary care hospital, Belgaum. Journal of Pharmaceutical and Biomedical Sciences. 17(17): 1-5.

Guide to the Elimination of Multidrugresistant Acinetobacter baumannii Transmission in Healthcare Settings; an APIC Guide 2010.

Hariom Sharan, Neeraj Katare, Aparna Pandey, Ganesh Shivmurti Bhatambare, Trupti Bajpai. 2016. Emergence of Hospital Acquired Carbapenem Resistant Non Fermenters in Teaching Institute. Journal of Clinical and Diagnostic Research. 10(12): 20-23.

Jayapriya Sukumaran, Lata Sriram, Sumathi.G. 2014. Nonfermentative gram negative bacilli- characterization and antibiotic resistant pattern study from a tertiary care hospital. Indian Journal of Basic and Applied Medical Research. 3(4): 227-232.

Juyal D, Prakash R, Shankarnarayan SA, Sharma M, Negi V, Sharma N. 2013.
Prevalence of non fermenting gram negative bacilli and their in vitro susceptibility pattern in a tertiary care hospital of Uttarakhand. A study from foothills of Himalayas. Saudi Journal for Health Sciences. 2(2): 108-112.

Kamalraj M, Sivashankari S, Thamarai S, Apurba Shankar Sastry. 2015. Study on Non fermenting gram negative bacilli from various clinical samples in a tertiary care hospital. Int J Bio. Med Res. 6(4):5230-5235.

Kiran Chawla, Shashidhar Vishwanath and Frenil C Munim. 2013. Non-fermenting Gram negative Bacilli other than Pseudomonas aeruginosa and Acinetobacter spp. Causing Respiratory Tract Infections in a Tertiary Care Centre. J Glob Infect Dis. 5(4): 144148.

Kollef, M.H., A. Shorr, Y.P. Tabak, V. Gupta, L. Z. Liu and R.S. Johannes. 2005. Epidemiology and outcomes of Health care associated pneumonia. American Journal of chest infections, New York. 128: 3854-3862.

Koneman EW, Winn WC Jr. Allen SD, Janda WM, Procop GW, Schreckenberger PC, Woods GL. 2006. Koneman's colour atlas and text book of diagnostic Microbiology. $6^{\text {th }}$ ed. Philadelphia: Lippincot Williams and WIkins Company. 303-91.

Malini A, Deepak EK, Gokul BN, Prasad SR. 2009. Non-fermenting gram negative bacilli infections in a tertiary care hospital in Kolar Karnataka. $J$ Lab Physicians. 1(2): 62-66.

Meharwal SK, Taneja N, Sharma SK, Sharma M. 2002. Complicated nosocomical UTI caused by nonfermenters. Indian Journal of Urology. 18(2): 123-128.

Mehta M, Dutta P, Gupta V. Bacterial isolates from burn wound infections and their antibiogram: An eight year study. Indian Journal of Plastic surgery. 2007; 
40(1): 25-28.

Minhas Akbar, Muhammad Zahid, Pir Asmat Ali, Aftab Alam Sthanadar, Mudassir Shah, Iram Alam Sthanadar, Muhammad Kaleem, Muhammad Aslam, Khayyam, Zahirullah, Syeda Mahreen Ul Hassan, Noor Jehan, Muhammad Ismail Khan. 2014. Isolation and Identification of MultiDrug Resistant Strains of Non-Lactose Fermenting Bacteria from Clinical Isolates. Open Journal of Medical Microbiology. 4: 115-123.

Pollack M, G. L. Mandell, R Dolan and J.E. Bannett. 1995. Principle and practices of infectious disease. New York. 18202003

Ronald J. Zabransky and Fred E. Day. 1969. Identification of Nonfermenting Gramnegative Bacilli in the Clinical Laboratory Applied Microbiology. 17(2): 331-332.

Shahla Mansouri, Mozhdeh Razavi, Fatemeh Norouzi, Sasan Gholamhoseinian Najar. 2012. Prevalence of $\beta$-Lactamase Production and Antimicrobial Susceptibility of Multidrug Resistant Clinical Isolates of Non-Fermenting Gram Negative Bacteria from Hospitalized Patients in Kerman/Iran. Jundishapur J Microbiol. 5(2): 406-410.
Sidhu S, Arora U, Devi P. 2010. Prevalence of nonfermentative gram negative bacilli in seriously ill patients with bacteremia. JK Science. 12: 168-171.

Sundaram Mohan, Khaja Mohiddin Shaik, Anandi Vishwanathan. 2016 Prevalence and antibiogram of Pseudomonas aeruginosa and Acinetobacter baumannii in the clinical samples from tertiary care hospital. Indian J Microbiol Res. 3(3): 275-278.

Syed Haroon Hussain1, Sukesh Kumar B. Y2, Kondal Rao. 2015. Study of carbapenem resistance in nonfermenting gram negative isolates. Journal of Evidence Based Med. and Healthcare. 2(34): 2349-2570.

Vijaya D, Kamala, Bavani S, Veena M. 2000. Prevalence of non-fermenters in clinical specimens. Indian J. Med. Sci. 54: 8791.

Vikas Jain, V.K.Ramnani and Navinchandra Kaore. 2015. Antimicrobial Susceptibility Pattern amongst Aerobic Bacteriological Isolates in Infected Wounds of Patients Attending Tertiary Care Hospital in Central India. Int.J.Curr.Microbiol.App.Sci. 4(5): 711719.

\section{How to cite this article:}

Jitendra, Shiv Kumar, Sheetal Sharma, Jogender and Suman Rishi. 2017. Isolation and Antibiogram of Nonfermentative Gram Negative Bacilli in various Clinical Specimens in a Tertiary Care Hospital, Jaipur', Int.J.Curr.Microbiol.App.Sci. 6(12): 1369-1380. doi: https://doi.org/10.20546/ijcmas.2017.612.153 